\title{
Bioactivities of Chukrasia tabularis (A. Juss.)
}

\author{
Sharmin Aktar', Marzia Bilkiss², Faiza Tahia ${ }^{3}$, Md. Al Amin Sikder ${ }^{3}$, \\ Ridwan B. Rashid ${ }^{4}$ and Mohammad A. Rashid ${ }^{3}$
}

\author{
${ }^{1}$ Department of Pharmacy, State University of Bangladesh, Dhanmondi-1205, Bangladesh \\ ${ }^{2}$ Department of Plant Pathology, Faculty of Agriculture, Bangladesh Agricultural University, Mymensingh, Bangladesh \\ ${ }^{3}$ Phytochemical Research Laboratory, Department of Pharmaceutical Chemistry Faculty of Pharmacy, \\ University of Dhaka, Dhaka-1000, Bangladesh \\ ${ }^{4}$ Department of Microbiology, University of Dhaka, Dhaka-1000, Bangladesh
}

Received: May 02, 2015; Accepted: June 11, 2015; Published (Web): July 21, 2015

\begin{abstract}
The methanol extracts of bark and leaves of Chukrasia tabularis and their organic and aqueous soluble materials were subjected to screenings for antioxidant, cytotoxic, thrombolytic, membrane stabilizing, antimicrobial, analgesic and antidiarrhoel activities. In the DPPH free radical scavenging assay, the methanolic extract of bark of C. tabularis and the aqueous soluble fraction of methanol extract of leaves of $C$. tabularis revealed the highest free radical scavenging activity with $\mathrm{IC}_{50}$ values of $2.95 \mu \mathrm{g} / \mathrm{ml}$ and $5.31 \mu \mathrm{g} / \mathrm{ml}$, respectively. The pet ether soluble fraction of methanolic extract of leaves and bark of $C$. tabularis displayed the highest cytotoxic potential having $\mathrm{LC}_{50}$ values $0.0167 \mu \mathrm{g} / \mathrm{ml}$ and $3.89 \mu \mathrm{g} / \mathrm{ml}$, as compared to standard vincristine sulphate $\left(\mathrm{LC}_{50}\right.$ value of $\left.0.45 \mu \mathrm{g} / \mathrm{ml}\right)$. During thrombolytic assay, the aqueous soluble fraction of leaves and carbon tetrachloride soluble fraction of bark of $C$. tabularis showed $34.04 \%$ and $56.37 \%$ clot lysis, respectively. In the membrane stabilizing assay, the carbontetrachloride and aqueous soluble materials of methanol extract of leaf inhibited $21.03 \%$ and $49.68 \%$ hypotonic solution- and heat-induced haemolysis of RBC, respectively. The crude extract of leaves of $C$. tabularis exhibited mild antibacterial activity, while that of leaves and bark revealed significant central analgesic activity at $400 \mathrm{mg} / \mathrm{kg}$ body weight. The crude extracts demonstrated significant peripheral analgesic activity at 200- and 400$\mathrm{mg} / \mathrm{kg}$ body weight. On the other hand, the crude extract of leaves of $C$. tabularis revealed significant antidiarrhoel activity.
\end{abstract}

Key words: Chukrasia tabularis, antioxidant, DPPH, thrombolysis, antibacterial, analgesic, antidiarrhoel.

\section{Introduction}

Chukrasia tabularis (A. Juss.) (English name: Burmese almond wood; Bengali name: Chikrassi) belongs to the family Meliaceae. It is an evergreen deciduous, sometimes fairly large tree up to $30 \mathrm{~m}$ in height and is widely distributed in South East Asia including Bangladesh. Traditionally various parts of $C$. tabularis are used as analgesic, astringent, antipyretic, antidiarrhoeal activities. (Nakatani et al., 2004). Previous phytochemical investigations with $C$. tabularis led to the isolation of triterpenes, (Roy et al., 2006) and limonoids (Xhang et al., 2007).

As part of our ongoing investigation with medicinal plants of Bangladesh (Tahia et al., 2015, Sikder et al., 2011), the crude methanol extracts of the bark and leaves of $C$. tabularis as well as their aqueous and organic soluble fractions were studied for the antioxidant potential in terms of total phenolic content and free radical scavenging, cytotoxic, thrombolytic, membrane stabilizing, antimicrobial, analgesic and antidiarrhoel activities for the first time and we, here in, report the results of our preliminary investigations.

\section{Materials and Methods}

Collection of plant materials and extraction: The bark and leaves of $C$. tabularis were collected in April 2014. Voucher specimens (Accession no: DACB-40132) for the plant have been maintained in Bangladesh National Herbarium, Dhaka, Bangladesh for future reference.

The collected plant materials were cleaned, sun dried and pulverized. The bark and leaves in powdered form (500 $\mathrm{g}$ each) were separately soaked in 2.0 liters of

Correspondence to: Mohammad A. Rashid; Tel.: +880-2-9661900, Extn. 8137; E-mail: rashidma@du.ac.bd 
methanol at room temperature for 7 days. The extracts were filtered through fresh cotton bed and finally with Whatman filter paper number 1 . The filtrates were concentrated with a rotary evaporator at reduced temperature and pressure. An aliquot $(5 \mathrm{~g})$ of each of the concentrated methanol extracts was fractionated by the modified Kupchan partitioning protocol (Van Wagenen $e t$ al., 1993) and the resultant partitionates were evaporated to dryness to yield pet-ether (PESF), carbon tetrachloride (CTCSF), chloroform (CSF) and aqueous (AQSF) soluble materials (Table 1). The residues were then stored in a refrigerator until further use.

Drugs and chemicals: Acetic acid (Merck, Germany), Tween-80 (BDH Chemicals, UK), normal saline solution (Beximco Infusion Ltd., Bangladesh), Morphine (Gonoshastho Pharmaceuticals), Diclofenac sodium, Glibenclamide and loperamide were used in this investigation. The extractives of the plant were dissolved in $1 \%$ Tween 80 and subsequently in $0.9 \%$ normal saline separately at a concentration of $10 \mathrm{mg} / \mathrm{ml}$ and the required dose was administered orally according to the weight of the mice.

Table 1. Kupchan partitionates of $C$. tabularis leaf and bark.

\begin{tabular}{ccc}
\hline $\begin{array}{c}\text { Crude extract/ } \\
\text { Fractions }\end{array}$ & Leaf $(\mathrm{g})$ & Bark $(\mathrm{g})$ \\
\hline ME & 5.00 & 5.00 \\
PESF & 0.65 & 0.85 \\
CTCSF & 0.55 & 0.75 \\
CSF & 0.30 & 0.40 \\
AQSF & 2.50 & 2.30 \\
\hline
\end{tabular}

$\mathrm{ME}=$ Methanolic crude extract; $\mathrm{PESF}=$ Pet-ether soluble fraction; $\mathrm{CTCSF}=$ Carbon tetrachloride soluble fraction; $\mathrm{CSF}=$ Chloroform soluble fraction; $\mathrm{AQSF}=$ Aqueous soluble fraction.

Animals: Swiss-albino mice of either sex aged 4-5 weeks were used for the experiment. The average weight of the mice used was 20-25 g. The procedures in this study for animal handling were performed in accordance with the Animal Resources Branch of the International Center for Diarrheal Disease and Research, Bangladesh (ICDDR, B). All efforts were made to minimize animals suffering and to reduce the number of animals used in the experiments. They were kept in standard environmental condition (at $24.0 \pm 1{ }^{\circ} \mathrm{C}$ temperature and $55-65 \%$ relative humidity and $12 \mathrm{~h}$ light/12 h dark cycle) for a week for acclimation after their purchase and fed with rodent feed purchased from International Centre for Diarrhoeal Diseases and Research, Bangladesh (ICDDR,B) and water.

Total phenolic content: The total phenolic content of the extractives was determined with Folin-Ciocalteau reagent by using the method developed by Skerget et. al., (2005).

DPPH free radical scavenging assay: Following the method developed by Brand-Williams et al., (1995), the antioxidant activity of the test samples was assessed by evaluating the scavenging activities of the stable 1,1diphenyl-2-picrylhydrazyl (DPPH) free radical by using synthetic antioxidants, butylated hydroxytoluene (BHT) and ascorbic acid as reference standards.

Brine shrimp lethality bioassay: This technique was applied for the determination of general toxic properties of the dimethylsulfoxide (DMSO) solution of plant extractives against Artemia salina in a single day assay (Meyer et al., 1982). Vincristine sulphate was used as the positive control.

Thrombolytic activity: The method developed by Prasad et al., (2006) and Harbertson et al., (2006) was used to determine the thombolytic activity by using streptokinase (SK) as positive control.

Membrane stabilizing activity: The membrane stabilizing activity of the extractives was evaluated by the inhibition of heat- and hypotonic solution-induced haemolysis of human erythrocytes following the method developed by Omale et al., (2008).

Antimicrobial screening: Antimicrobial activity was determined by the disc diffusion method (Bauer et al., 1966).

Tail immersion technique for peripheral analgesic assay: The tail immersion method was carried out as an alternative method to evaluate peripheral analgesic activity (Aydin et al., 1999).

Antidiarrheal activity: Antidiarrhoeal activity was assessed by the method developed by Shoba and Thomas, 2001. Castor oil was used to induce diarrhea.

Statistical analysis: For all bioassays, three replicates of each sample were used for statistical analysis and the values are reported as mean \pm SD. 


\section{Results and Discussion}

The crude methanol extracts of bark and leaves of $C$. tabularis, as well as their Kupchan partitionates, were evaluated for the total phenolic content, free radical scavenging, cytotoxic, thrombolytic, membrane stabilizing, antimicrobial, analgesic and antidiarrhoel activities.

The total phenolic content of the leaves of $C$. tabularis was found in the range of $3.91 \pm 0.23$ to $21.07 \pm$ $0.45 \mathrm{mg}$ of GAE/g of extractives, with the highest amount of phenolics $(21.07 \pm 0.45 \mathrm{mg}$ ) was observed in the carbon tetrachloride soluble fraction. Again, the total phenolic content of the bark of $C$. tabularis was found in the range of $25.21 \pm 0.27$ to $139.53 \pm 0.63 \mathrm{mg}$ of $\mathrm{GAE} / \mathrm{g}$ of extractives, with the highest amount of phenolics (139.53 $\pm 0.63 \mathrm{mg}$ ) being observed in the methanol extract (Table 2).

In the DPPH free radical scavenging assay, the aqueous soluble fraction of leaves of $C$. tabularis revealed maximum free radical scavenging activity having $\mathrm{IC}_{50}$ value of $5.31 \pm 0.88 \mu \mathrm{g} / \mathrm{ml}$ while standard ascorbic acid showed $\mathrm{IC}_{50}$ value of $5.80 \pm 0.21 \mu \mathrm{g} / \mathrm{ml}$. Among the test samples of bark of $C$. tabularis, the methanol extract demonstrated the highest free radical scavenging activity with $\mathrm{IC}_{50}$ value of $2.95 \pm 0.29 \mu \mathrm{g} / \mathrm{ml}$ (Table 2).

Table 2. Total phenolic content, free radical scavenging and cytotoxic activities of $C$. tabularis.

\begin{tabular}{|c|c|c|c|c|}
\hline Plant & $\begin{array}{l}\text { Sample/ } \\
\text { Standard }\end{array}$ & $\begin{array}{c}\text { Total phenolic content } \\
\text { (mg of GAE/gm of extract) }\end{array}$ & $\begin{array}{l}\text { DPPH Free radical scavenging } \\
\text { activity }\left(\mathrm{IC}_{50} \mu \mathrm{g} / \mathrm{ml}\right)\end{array}$ & $\begin{array}{l}\text { Cytotoxicity } \\
\left(\mathrm{LC}_{50} \mu \mathrm{g} / \mathrm{ml}\right)\end{array}$ \\
\hline \multirow{5}{*}{ Leaf } & $\mathrm{ME}$ & $14.00 \pm 0.67$ & $7.39 \pm 0.43$ & $12.912 \pm 0.45$ \\
\hline & PESF & $3.91 \pm 0.23$ & $43.08 \pm 0.23$ & $0.0167 \pm 0.08$ \\
\hline & CTCSF & $21.07 \pm 0.45$ & $20.70 \pm 0.76$ & $10.27 \pm 0.62$ \\
\hline & CSF & $10.28 \pm 0.56$ & $15.20 \pm 0.65$ & $21.8 \pm 0.44$ \\
\hline & AQSF & $6.84 \pm 0.33$ & $5.31 \pm 0.88$ & $4.36 \pm 0.59$ \\
\hline \multirow{5}{*}{ Bark } & $\mathrm{ME}$ & $139.53 \pm 0.63$ & $2.95 \pm 0.29$ & $13.8 \pm 0.76$ \\
\hline & PESF & $25.21 \pm 0.27$ & $21.40 \pm 0.77$ & $10.05 \pm 0.23$ \\
\hline & CTCSF & $66.60 \pm 0.46$ & $8.81 \pm 0.42$ & $4.46 \pm 0.63$ \\
\hline & $\mathrm{CSF}$ & $76.28 \pm 0.55$ & $13.53 \pm 0.35$ & $36.46 \pm 0.54$ \\
\hline & AQSF & $131.81 \pm 0.23$ & $410.72 \pm 0.47$ & $3.89 \pm 0.84$ \\
\hline \multirow{3}{*}{ Standards } & VS & - & - & $0.44 \pm 0.01$ \\
\hline & BHT & - & $27.70 \pm 0.54$ & - \\
\hline & Ascorbic acid & - & $5.40 \pm 0.21$ & - \\
\hline
\end{tabular}

$\mathrm{ME}=$ Methanolic crude extract PESF $=$ Pet-ether soluble fraction; $\mathrm{CTCSF}=\mathrm{Carbon}$ tetrachloride soluble fraction; $\mathrm{CSF}=\mathrm{Chloroform}$ soluble fraction; $\mathrm{AQSF}=$ Aqueous soluble fraction; $\mathrm{BHT}=$ Butylated hydroxytoluene; VS= Vincristine sulfate.

In the brine shrimp lethality bioassay, the pet ether soluble fraction of leaves of $C$. tabularis displayed the highest cytotoxic potential with $\mathrm{LC}_{50}$ value $0.0167 \pm 0.08$ $\mu \mathrm{g} / \mathrm{ml}$ as compared to $0.44 \pm 0.01 \mu \mathrm{g} / \mathrm{ml}$ for vincristine sulphate. On the other hand, the pet ether soluble fraction of bark of $C$. tabularis, revealed the highest cytotoxic potential with $\mathrm{LC}_{50}$ value $3.89 \pm 0.84 \mu \mathrm{g} / \mathrm{ml}$. This suggested the presence of potent bioactive components in the above mentioned extractives (Table 2).

The extractives of the bark and leaves of $C$. tabularis were assayed for thrombolytic activity to determine the ability to lyse clots. Upon addition of $100 \mu 1$ streptokinase (SK), a positive control (30,000 I.U.) to the clots of human blood, and subsequent incubation for 90 minutes at $37^{\circ} \mathrm{C}$, showed $65.88 \%$ lysis of the clot as compared to distilled water showing a negligible lysis of clot $(3.74 \%)$. In this study, the aqueous soluble fraction of leaf of $C$. tabularis showed highest thrombolytic activity of $56.37 \pm 0.88 \%$ while the carbon tetra chloride soluble fraction of bark of C. tabularis showed maximum activity of $34.04 \pm 0.23 \%$ (Table 3).

The membrane stabilizing activity of the extractives of the leaves of $C$. tabularis was also determined. They significantly protected the lysis of human erythrocyte membrane induced by heat and hypotonic solution, as compared to the standard acetyl salicylic acid. In hypotonic solution- and heat-induced conditions, the carbon tetrachloride and aqueous soluble fractions of leaves of $C$. tabularis inhibited haemolysis of RBCs by $21.03 \pm 0.84 \%$ and $49.68 \pm 0.21 \%$ as compared to $72.2 \%$ and $42.2 \%$ revealed by acetyl salicylic acid (ASA, 0.10 $\mathrm{mg} / \mathrm{ml}$ ), respectively (Table 4). 
Table 3. Thrombolytic activity of $C$. tabularis.

\begin{tabular}{lcc}
\hline \multirow{2}{*}{ Sample } & \multicolumn{2}{c}{ \% clot lysis } \\
\cline { 2 - 3 } & Leaf & bark \\
\hline ME & $37.68 \pm 0.55$ & $5.89 \pm 0.33$ \\
PESF & $23.89 \pm 0.44$ & $21.63 \pm 0.23$ \\
CTCSF & $29.99 \pm 0.34$ & $11.93 \pm 0.11$ \\
CSF & $41.78 \pm 0.23$ & $34.04 \pm 0.23$ \\
AQSF & $56.37 \pm 0.88$ & $9.44 \pm 0.56$ \\
Blank & \multicolumn{2}{c}{$3.74 \pm 0.55$} \\
SK & \multicolumn{2}{c}{$65.88 \pm 1.08$} \\
\hline
\end{tabular}

SK = Streptokinase (Positive control); Water (negative control)

Table 4. Percent inhibition of hypotonic solution- and heatinduced hemolysis of erythrocyte membrane by leaf of C. tabularis.

\begin{tabular}{lcc}
\hline Sample & \multicolumn{2}{c}{ Leaf } \\
\cline { 2 - 3 } & Hypnotic solution induced & Heat-induced \\
\hline ME & $14.34 \pm 0.66$ & $49.68 \pm 0.23$ \\
PESE & $0.90 \pm 0.55$ & $8.82 \pm 0.43$ \\
CTCSF & $21.03 \pm 0.84$ & $32.27 \pm 0.56$ \\
CSF & $1.47 \pm 0.67$ & $2.15 \pm 0.44$ \\
AQSF & $57.4 \pm 0.84$ & $49.68 \pm 0.32$ \\
ASA & $72.2 \pm 0.47$ & $42.2 \pm 0.23$ \\
\hline
\end{tabular}

The extractives of the leaves of $C$. tabularis were screened for antibacterial activity against gram positive and gram negative bacteria at a concentration of $400 \mu \mathrm{g} /$ disc. The methanolic extract of the leaves of $C$. tabularis exhibited mild antimicrobial activity. The inhibitory activity of the extractives was compared with ciprofloxacin as standard (Table 5)

The methanol extract of the leaves of $C$. tabularis showed significant peripheral analgesic activity at 400 $\mathrm{mg} / \mathrm{kg}$ body weight after 30 minutes of administration. Both 200- and 400-mg/kg body weight showed significant central analgesic effect after 60 and 90 minutes respectively. The methanol extract of the bark of $C$. tabularis revealed significant activity after 30 minutes at $400 \mathrm{mg} / \mathrm{kg}$ body weight (Table 6 ).

The methanolic extract of leaves of $C$. tabularis showed significant anti-diarrheal activity at the first, second, third and fourth hour (Table 7)

Table 5. Antibacterial activity of leaf of $C$. tabularis.

\begin{tabular}{|c|c|c|c|c|c|c|}
\hline \multirow[t]{2}{*}{ Test microorganisms } & \multirow[b]{2}{*}{ ME } & \multicolumn{5}{|c|}{ Diameter of zone of inhibition (mm) } \\
\hline & & PESF & CTCSF & CSF & AQSF & Ciprofloxacin \\
\hline Bacillus cereus & 9.0 & & & & & 40.0 \\
\hline B. megaterium & 11.0 & & & & & \\
\hline B. subtilis & 9.0 & & & & & 40.0 \\
\hline Sarcina lutea & 10.0 & & & & & 50.0 \\
\hline Staphylococcus aureus & 10.0 & & & & & 53.0 \\
\hline Escherichia coli & 9.0 & & & & & 47.0 \\
\hline Salmonella Paratyphi & 10.0 & & & & & 51.0 \\
\hline$S$. Typhi & 100 & & & & 10.0 & 49.0 \\
\hline Shigella boydii & 11.0 & 9.0 & & & & 47.0 \\
\hline Sh. dysenteriae & 10.0 & & & & & 47.0 \\
\hline Pseudomonas aeruginosa & 10.0 & & & & & 45.0 \\
\hline Vibrio mimicus & & & & & & 45.0 \\
\hline V. parahaemolyticus & 9.0 & & & & & 48.0 \\
\hline Aspergillus niger & 13.0 & & & & & 47.0 \\
\hline Candida albicans & 8.0 & & & & & 45.0 \\
\hline Sacharomyces cerevisiae & 12.0 & & & 8.0 & & 45.0 \\
\hline
\end{tabular}


Table 6. Effect of methanol extracts of $C$. tabularis on tail immersion test in mice.

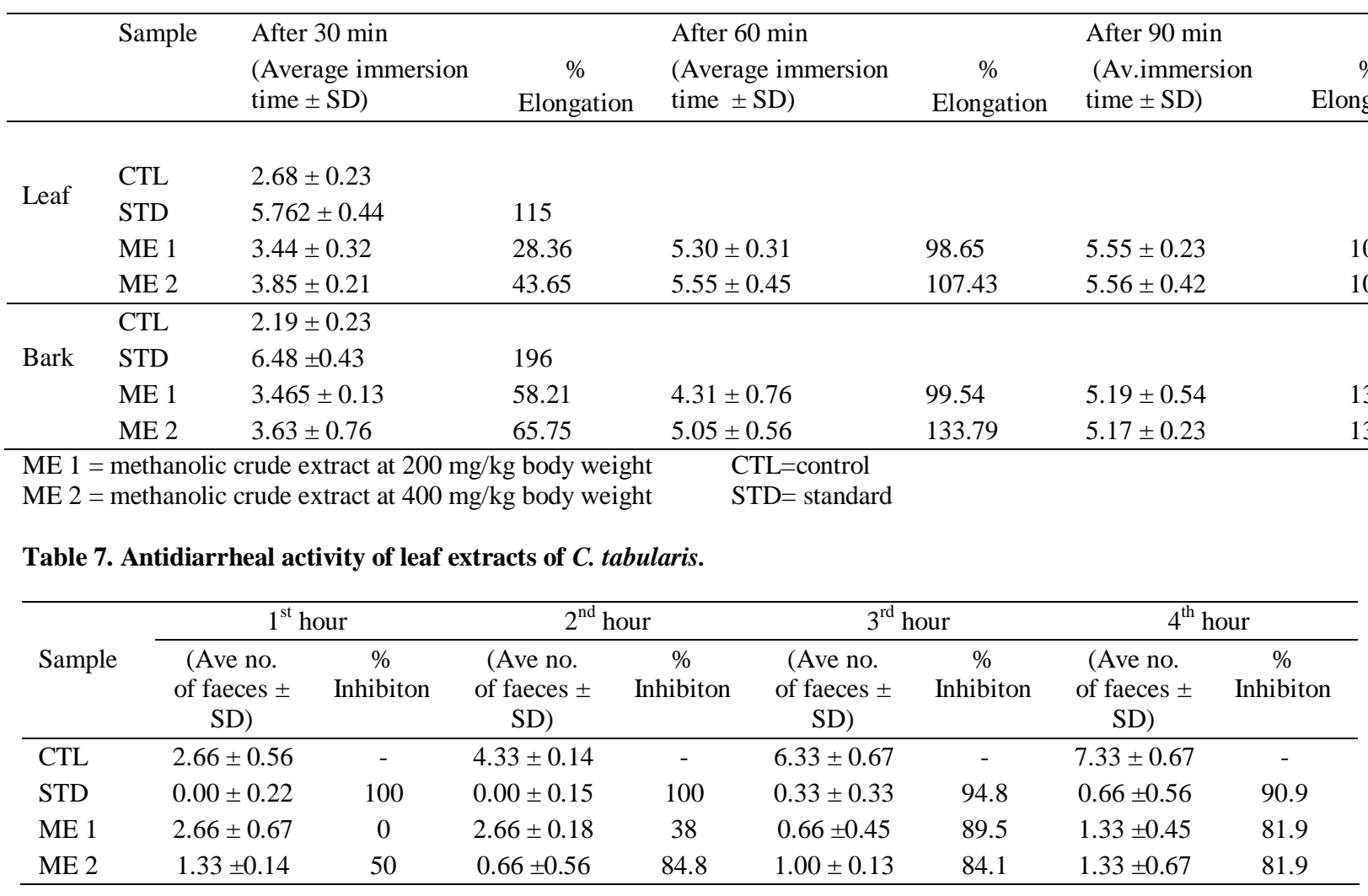

\section{Conclusion}

It is clearly evident from the above findings that the bark and leaves of $C$. tabularis have significant free radical scavenging, cytotoxic, membrane stabilizing, thrombolytic, central and peripheral analgesic, and antidiarrhel properties. The plant also exhibited mild antimicrobial potential. The bark and leaves of $C$. tabularis can be used for inflammation, pain etc. Our findings justify the traditional uses of the plant species. Therefore, the plant is a good candidate for further chemical investigations to isolate the active constituents.

\section{References}

Aydin, S., Demir, T., Ozturk, Y. and Baser, K.H. 1999. Analgesic activity of Nepeta italica L. Phytother Res. 13, 20-23.

Bauer, A.W., Kirby, W.M.M., Sheriss, J.C. and Turck, M. 1966. Antibiotic susceptibility testing by standardised single method. Am. J. Clin. Pathol. 45, 493-496.

Brand-Williams, W., Cuvelier, M.E. and Berset, C. 1995. Use of free radical method to evaluate antioxidant activity. Lebensm. Wiss. Technol. 28, 25-30.
Harbertson, J. and Spayd, S. 2006. Measuring phenolics in the winery. Am. J. Enol. Vitic. 57, 280-288.

Meyer, B.N., Ferringni, N.R., Puam, J.E., Lacobsen, L.B., Nichols, D.E. and McLaughlin, J.L. 1982. Brine shrimp: a convenient general bioassay for active constituents. Planta Med. 45, 31-32.

Nakatani, M., Abdelgaleil, S.A.M., Saad, M.M.G., Huang, R.C., Doe, M. and Iwagawa, T. 2004. Phragmalin limonoids from Chukrasia tabularis. Phytochemistry 65, 2833-2841.

Omale, J. and Okafor, P.N. 2008. Comparative antioxidant capacity, membrane stabilization, polyphenols composition and cytotoxicity of the leaf and stem of Cissus multistriata. Afr. J. Biotechnol. 7, 3129-3133.

Prasad, S., Kashyap, R.S., Deopujari, J.Y., Purohit, H.J., Taori, G.M. and Daginawala, H.F. 2007. Effect of Fagonia arabica (Dhamasa) on in vitro thrombolysis, BMC Complement. Alternat. Med. 7, 36 doi: 10.1186/1472-68827-36.

Roy, A. and Saraf, S. 2006. Limonoids: Overview of significant Bioactive Triterpenes distributed in Plant Kingdom. Biol. Pharm. Bull. 29, 191-201.

Shoba, F.G. and Thomas, M. 2001. Study of antidiarrhoeal activity of four medicinal plants in castor oil induced diarrhea. J. Ethnopharmacol. 76, 73-76. 
Skerget, M., Kotnik, P., Hadolin, M., Hras, A., Simonic, M. and Knez, Z. 2005. Phenols, proanthocyanidins, flavones and flavonols in some plant materials and their antioxidant activities. Food Chem. 89, 191-198.

Sikder, M.A., Hossian, A.K.M.N., Siddique, A.B., Ahmed, M., Kaisar, M.A. and Rashid, M.A. 2011. In vitro antimicrobial screening of four reputed bangladeshi medicinal plants. Pharmacog. J. 3, 72-75.

Tahia, F., Sikder, M. A., Sayeed, M.A. and Rashid, M.A. 2014. Bioactivities of Murraya koenigii (Linn.) and Adina cordifolia (Roxb.). Bang. Pharm. J. 18, 25-29.
Vanwagenen, B.C., Larsen, R., Cardellina, J.H., Randazzo, D., Lidert, Z.C. and Swithenbank, C. 1993. Ulosantoin, a potent insecticide from the sponge Ulosa ruetzleri. J. Org. Chem. 58, 335-337.

Xhang, C.R., Yang, S.P., Liao, S.G., Fan, C.Q., Wu, Y. and Yue, J.M. 2007. Chuktabularins A-D, four new limonoids with unprecedented carbon skeletons from the stem bark of Chukrasia tabularis. Org. Lett. 9, 3383-3386. 